\section{Comment on "Physical Model for the Decay and Preservation of Marine Organic Carbon"}

\author{
Bernard P. Boudreau, ${ }^{1 *}$ Carol Arnosti, ${ }^{2}$ Bo Barker Jørgensen, ${ }^{3}$ Donald E. Canfield ${ }^{4}$
}

Rothman and Forney (Reports, 1 June 2007, p. 1325) described a model for the decay of marine organic carbon. However, the enzyme deactivation rates required by their model are too fast compared with available data, and the model fails to explain the similarity in observed decay rate constants from different experiments. Alternative models provide equally good fit to the observed temporal trend in decay rate constants.

$\mathrm{R}$ othman and Forney (l) investigated the degradation and preservation of marine organic carbon, and their study contains interesting ideas that may help improve the understanding of this environmentally and geologically important topic. However, we disagree with several aspects of their proposed model.

First, Rothman and Forney argue that the decomposition rate of organic matter in sediments is controlled by the rate of diffusion of extracellular enzymes from the secreting bacteria. Diffusion becomes rate limiting because the authors hypothesize that the enzymes are rapidly deactivated, with a rate constant $\alpha$; therefore, the value of $\alpha$ is crucial to the validity of their model. The rate of deactivation demanded by the model is unreasonably high, however, and is not in accordance with experimental data on enzyme activity. Specifically, Rothman and Forney state that $\beta \cdot r_{p} \approx 5$, where $\beta \equiv(\alpha / D)^{1 / 2}$, $D$ is the diffusion coefficient of enzymes, and $r_{p}$ is the typical distance between microbes. For bacterial populations of $10^{9}$ to $10^{10}$ per $\mathrm{cm}^{3}$ (2), $r_{p}$ is about $10 \mu \mathrm{m}$. Using this $r_{p}$ value and $D=10^{-6} \mathrm{~cm}^{2} \mathrm{~s}^{-1}$ for moderate-sized organic molecules (3), we calculate $\alpha$ to be $10^{2} \mathrm{~s}^{-1}$. Thus, the calculated mean lifetime of an enzyme under reasonable natural conditions is predicted to be only $\sim 0.01 \mathrm{~s}$. Conversely, experimental evidence (4-6) indicates that enzymes are stable for at least minutes to hours in solution or days to weeks on surfaces, that is, $\alpha=10^{-6}$ to $10^{-2} \mathrm{~s}^{-1}$, and can diffuse effectively over millimeter distances $(6,7)$. This discrepancy appears to invalidate the Rothman and Forney model.

${ }^{1}$ Department of Oceanography, Dalhousie University, Halifax, Nova Scotia B3H 4]1, Canada. 'Department of Marine Sciences, University of North Carolina, Chapel Hill, NC 275993300, USA. ${ }^{3}$ Max Planck Institut für Marine Mikrobiologie, Celsiusstrasse 1, D-28359 Bremen, Germany. ${ }^{4}$ Nordic Center for Earth Evolution and Institute of Biology, University of Southern Denmark, Campusvej 55, 5230 Odense M, Denmark.

*To whom correspondence should be addressed. E-mail: bernie.boudreau@dal.ca
Second, according to the Rothman and Forney model, the rate constant $k$ for organic matter decay should depend on the sediment geometry, the amount of mixing (if any), and the presence or absence of sediment, because enzyme diffusion and the deactivation mechanism depend on these factors. Thus, experiments that radically differ in these factors should produce substantially different $k$ values. Yet counter examples are easily identified. For example, in an experiment on anoxic decay of fresh organic matter (plankton) in a mixed vessel with no sediment, Harvey et al. (8) found that $k$ has a range of 0.0068 to

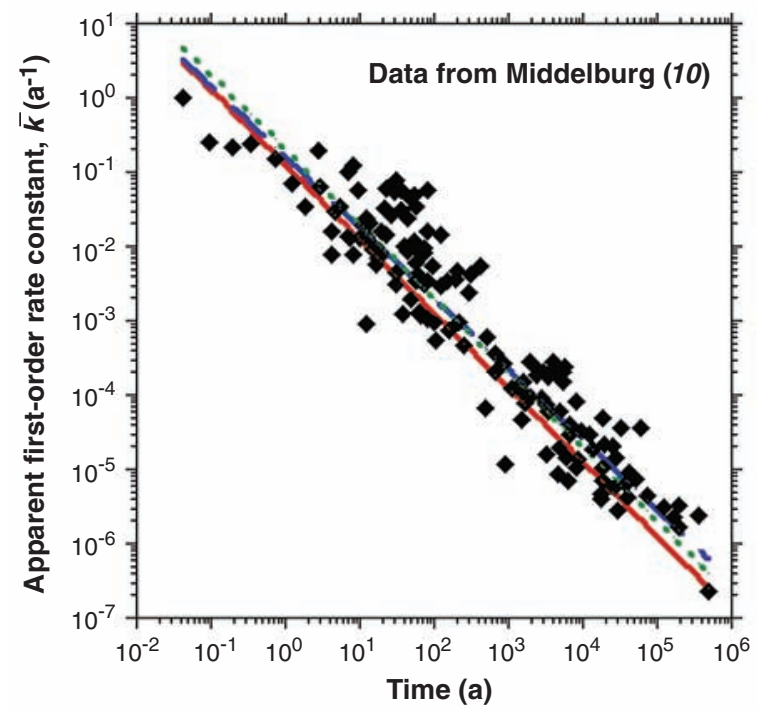

Fig. 1. Plot of the apparent first-order decay constant, $\bar{k}$, for organic matter in sediments as a function of time, as established with data from Middelburg (10). The dotted green line is Middelburg's best fit with a power law, i.e., $\bar{k}=0.16 \pm 0.02 t^{-0.95} \pm 0.01$. The red solid line is the prediction made with the continuum version of the intrinsic-reactivity model (11), using a gamma distribution for rate constant values and parameter values for $v$ and $a$ taken from (9), i.e., $\bar{k}=0.125 \pm 0.013(0.0003+t)^{-1}$. The dashed blue line is the predicted relationship from (1), i.e., $\bar{k}=0.2 \mathrm{t}^{-1}$. All of these equations capture the trend in these data. given by
$0.0080 \mathrm{~d}^{-1}$. Conversely, Westrich and Berner (9) conducted an anoxic organic matter decay experiment by adding fresh plankton to anoxic ent and measuring the rate of sulfide (8) values. This correspondence of rates sho not occur if the Rothman and Forney model is less, the alternative intrinsic-reactivity model, in its continuum version (10), can also predict this relationship. Specifically, the average rate of decay of a mass of organic matter (SOM text) is

$$
\bar{k}=\frac{v}{(a+t)}
$$

where $a$ is the initial age of the organic matter $a=0.0003$ years (11), the continuum version of the intrinsic-reactivity model generates the relation $\bar{k}=0.125(0.0003+t)^{-1}$.

This function is plotted in Fig. 1 as the solid red line. For comparison, the Rothman and Forney derived equation for $\bar{k}$ is plotted as the dashed blue line, and Middelburg's best-fit power law is included as the dotted green line. The prediction from the continuum version of the intrinsicreactivity model is certainly as accurate as the Rothman and Forney model prediction, within the uncertainty of these data, over a span of eight orders of magnitude in both $\bar{k}$ and $t$. Thus, we contend that Rothman and Forney cannot claim any superiority based on consistency with the data in Fig. 1. Furthermore, Eq. 1 is arguably conceptually preferable because it suffers no singularity at $t=0$.

Because of these problems, we believe that the model proposed in (1) is not consistent with current knowledge about sedimentary organic decomposition and is thus incorrect. Intrinsic reactivity, as modified by likely clay-organic matter interactions, is in our opinion a much more viable model of this process. 


\section{References and Notes}

1. D. H. Rothman, D. C. Forney, Science 316, 1325 (2007).

2. J. L. Schmidt et al., Limnol. Oceanogr. 43, 976 (1999).

3. E. H. Oelkers, Geochim. Cosmochim. Acta 55, 3515 (1991).

4. S. D. Allison, Biogeochemistry 81, 361 (2006).

5. K. Ziervogel et al., Mar. Chem. 104, 241 (2007)

6. Y. A. Vetter, J. W. Deming, Microb. Ecol. 37, 86 (1999).

7. R. G. Wetzel, in Microbial Enzymes in the Aquatic

Environment, R. ]. Chróst, Ed. (Springer-Verlag, New York, 1991), pp. 6-28.
8. H. R. Harvey et al., Geochim. Cosmochim. Acta 59, 3367 (1995).

9. J. T. Westrich, R. A. Berner, Limnol. Oceanogr. 29, 236 (1984).

10. ]. J. Middelburg, Geochim. Cosmochim. Acta 53, 1577 (1989).

11. B. P. Boudreau, B. R. Ruddick, Am. J. Sci. 291, 507 (1991).

12. This work was supported by the Natural Sciences and Engineering Research Council of Canada, the U.S. Office of Naval Research (B.P.B.), the U.S. NSF (C.A.),
The Max-Planck Society (B.P.B.].) and the Danish National Research Foundation (D.E.C.)

\section{Supporting Online Material}

www.sciencemag.org/cgi/content/full/319/5870/1616b/DC1 SOM Text

Figs. S1 and S2

References

31 July 2007; accepted 25 February 2008

10.1126/science. 1148589 


\section{Science}

\section{Comment on "Physical Model for the Decay and Preservation of Marine Organic Carbon"}

Bernard P. Boudreau, Carol Arnosti, Bo Barker Jørgensen and Donald E. Canfield

Science 319 (5870), 1616.

DOI: $10.1126 /$ science. 1148589

ARTICLE TOOLS

SUPPLEMENTARY MATERIALS

RELATED

CONTENT

REFERENCES

PERMISSIONS http://science.sciencemag.org/content/319/5870/1616.2

http://science.sciencemag.org/content/suppl/2008/03/20/319.5870.1616b.DC1

http://science.sciencemag.org/content/sci/316/5829/1325.full

http://science.sciencemag.org/content/sci/319/5870/1616.3.full

This article cites 10 articles, 2 of which you can access for free http://science.sciencemag.org/content/319/5870/1616.2\#BIBL

http://www.sciencemag.org/help/reprints-and-permissions 